\title{
An Educational Module to Increase Engineering Students Knowledge of Work Zone Safety in Highway Construction
}

\section{Dr. Didier M Valdes, University of Puerto Rico at Mayaguez}

Dr. Didier Valdes is a professor at the University of Puerto Rico at Mayaguez. With more than 30 years of experience in engineering education, research, and administration, Dr. Valdes brings the combination of professional and practical experience to all his endeavors.

\section{Dr. Carla Lopez del Puerto, University of Puerto Rico, Mayaguez Campus}

Carla López del Puerto, Ph.D. is a Professor of Construction Engineering and Management in the Department of Civil Engineering at The University of Puerto Rico - Mayagüez Campus.

Dr. Alberto M. Figueroa-Medina, University of Puerto Rico at Mayaguez

Professor of Transportation Engineering from the Department of Civil Engineering and Surveying at the University of Puerto Rico at Mayaguez. Academic preparation includes a BS in Civil Engineering and an MS in Civil Engineering from UPRM, and a Ph.D. degree in Civil Engineering from Purdue University. Research interests include the evaluation of transit quality of service, effects of road geometric design, and road safety analysis. Has served as Member of two national research committees of the Transportation Research Board (TRB): Operational Effects of Geometrics (AHB65) and Safety Data, Analysis and Evaluation (ANB20). Former President and General Manager of the Metropolitan Bus Authority (MBA) and Former Executive Director of the Puerto Rico Integrated Transit Authority (PRITA).

Dr. Benjamin Colucci, University of Puerto Rico at Mayaguez

Ms. Rocío Juliana Sotomayor-Irizarry, University of Puerto Rico, Mayaguez Campus 


\title{
Developing an Educational Module to Increase Engineering Students' Knowledge of Highway Work Zones and Temporary Traffic Control Plans
}

\begin{abstract}
Motor vehicle crashes are the leading cause of fatalities of road users and construction workers in highway work zones. Temporary Traffic Control (TTC) plans are designed for the safe and effective movement of users along the road while allowing contractors to perform construction activities. The TTC plan must protect all road users, emergency and traffic incident responders, and construction workers and equipment, and must reduce the risks of having drivers traversing along the unfamiliar road or traffic conditions imposed by the work zone. The Manual on Uniform Traffic Control Devices for Streets and Highways (MUTCD), applicable to all streets and highways in the United States, provides standards and guidelines for the design of TTC applications based on factors such as highway type, traffic speed, vehicle mix and type, and location and duration of the work activity. An engineer must combine knowledge about road design, traffic operations, construction activities, and human factors to analyze the conditions and risks imposed by the work zone, anticipate potentially hazardous situations and select appropriate strategies and devices for the TTC plan. Furthermore, future engineers should consider the application of innovative solutions, such as those promoted by the Every Day Counts (EDC) program of the Federal Highway Administration (FHWA) to improve safety for all users and workers in work zones.
\end{abstract}

This paper presents the results of an online survey that assessed knowledge of the general population about highway work zones and TTC plans and the results of the development of an Interactive Learning Module (ILM) administered among second-year engineering students to increase their understanding of construction work zones and TTC plans. The survey results indicate that $65 \%$ of the respondents were not able to correctly identify the beginning of a highway work zone. Up to $45 \%$ of the survey respondents did not properly identify when to change lanes when encountering a closed lane. This lack of understanding of when to react to the altered road conditions in a work zone could expose construction workers to an increased risk of injuries and fatalities because of drivers not adjusting their normal behavior when approaching the work zone. An online training module about work zone safety and the design of TTC zones called WZILM was developed and administered to second-year engineering students that have not received formal road design training. WZILM included a pre-test, a mid-intervention assessment, and a post-test. WZILM was effective in increasing awareness and knowledge among engineering students on how to correctly implement TTC plans with the goal of reducing the risk of injuries and fatalities in work zones, thus improving overall safety for drivers and workers.

\section{Introduction}

A safe and efficient highway system is essential for the mobility and accessibility of persons and goods and to foster the socio-economic growth of the country. In many instances, roads can not be closed to traffic when maintenance and repair activities are needed to maintain the system in a state of good repair. Appropriate signage, markings, and other traffic control devices (TCDs) are required to provide positive guidance for motorists to safely traverse the work zone as well as to 
protect workers from serious injuries or fatalities [1]. Temporary Traffic Control (TTC) plans are designed for highway work zones to provide optimal functionality of the roadway as well as a safe and effective movement to road users when the normal function of the road is temporarily suspended. TTC plans also must protect workers, incident responders, and equipment.

Highway work zones fatalities in the United States amounted to 809 in 2017, of which 132 were workers [2]. Poorly planned work zones can result in excessive delays to motorists and other social impacts associated with the lives lost and serious injuries. Engineering students must understand the implications and risks of executing construction work in the vicinity of open traffic recognizing the potential for distracted or drunk drivers, road rage, and lack of compliance with traffic rules, among other behavior.

The Manual on Uniform Traffic Control Devices for Streets and Highways (MUTCD) is the national standard that includes all pertinent information related to the design, installation, and placement of TCDs. As defined by the MUTCD [1], "a TTC zone is an area of a highway where road user conditions are changed because of a work zone, an incident zone or a planned special event through the use of TTC devices, uniformed law enforcement officers, or other authorized personnel." A TTC zone may include signs, cones or drums, temporary pavement markings, and other devices depending on the type of activity being carried out. TCDs are used to warn and inform users of the changing road conditions and to channel traffic along the work zone. The extent and complexity of the TTC plan depend on factors such as road configuration, work type activity, traffic volumes and speeds, the duration and location of the work, and the road vehicle mix. The implementation of a TTC plan must support the safety and continuity of movement for motor vehicles, cyclists, pedestrians, and transit services along the work zone and provide access to adjacent property and utilities [1].

The MUTCD defines four main areas for a highway work zone: advance warning area, transition area, activity area, and termination area. The TTC design principles recognize that drivers should be aware of the changes that will occur along their path with sufficient time to adequately react to the changing environment. TTC zones could also include buffer spaces to consider the safety of the workers and the integrity of the equipment that performs construction activities on the traffic lanes. Positive protection devices can also be placed to provide workers appropriate protection from the traffic that goes through the TTC zone. Future engineering professionals must learn to analyze road users' behavior in the context of the work zone to decide the adequate protection needed for the TTC to increase worker safety.

\section{Instructional Videos}

Instructional videos have become an integral part of higher education. Video-based learning (VBL) uses audio and visual symbols to present information. VBL has been demonstrated to be an effective tool to engage in active learning in classrooms. Active learning is defined as activities that students do to construct knowledge and understanding [3]. Students who participated in a VBL activity to prepare for practical physiotherapy examinations exhibited better scores and reported reduced performance anxiety than students who did not participate in a VBL activity [4]. Kay describes the advantages of VBL as control over learning, improved study habits, and increased learning performance [5]. Other benefits of instructional videos include 
unlimited accessibility, individual learning environment, simple delivery, and improvement of motivation and concentration levels [6].

An effective VBL to which students can gain maximum knowledge requires three design elements: cognitive load, student engagement, and active learning [7]. The cognitive theory of multimedia learning builds on the cognitive load theory, noting that working memory has two channels to acquire and process information: a visual/pictorial channel and an auditory/verbalprocessing channel [8]. Another practice to maximize student learning in instructional videos is to consider student engagement. Keeping videos targeting learning goals, using a conversational style, and creating videos for the specific crowd and environment for which they will be used, increase student engagement [9]. Interpolated questions in videos improve learning and reduce mind wandering in students [10].

\section{Methodology}

A two-phase approach (see Figure 1) was used to assess knowledge and perceptions related to work zones and TTC zones. The first phase consisted of developing and administering a webbased survey to the university community, whereas the second phase consisted of developing and administering an online interactive learning module to engineering students.

\begin{tabular}{|c|c|c|c|}
\hline \multicolumn{2}{|c|}{ Phase 1} & \multicolumn{2}{|c|}{ Phase 2} \\
\hline $\begin{array}{l}\text { Web-Based } \\
\text { Survey } \\
\text { Development }\end{array}$ & $\begin{array}{l}\text { Web-Based } \\
\text { Survey } \\
\text { Administration }\end{array}$ & $\begin{array}{l}\text { Interactive } \\
\text { Learning Module } \\
\text { Development }\end{array}$ & $\begin{array}{l}\text { Interactive } \\
\text { Learning Module } \\
\text { Administration }\end{array}$ \\
\hline
\end{tabular}

Figure 1: Research Phases.

\section{Phase 1 Survey on Work Zone and TTC Knowledge and Perception}

The web-based survey was created to assess road user behavior and knowledge about work zones and TTC zones. The survey was designed using multiple-choice questions and statements. The subjects for phase 1 were recruited using convenience sampling through the university email system. An email was sent to members of the university community (students, faculty, and staff) inviting them to participate in the survey. Participant inclusion criteria included having a valid Puerto Rico driving license. The researchers obtained IRB approval and participation in the study was voluntary.

To understand the knowledge that survey participants have regarding work zones and TTC primary components, an illustration of a TTC zone with a stationary right lane closure on a divided highway was presented (see Figure 2). The text of the warning signs was shown in Spanish as required by local statutes. Lines A, B, C, and D refer to strategic points in the TTC zone. Line A identifies the start of the advance warning area (i.e., the position of the first warning sign shown to drivers). Line B was positioned at the last sign of the advance warning area. Line $C$ represents the beginning of the transition area (i.e., the start of the right-lane merging taper). Line D marks the start of the activity area. Using these four lines as references, subjects were asked to identify: where the construction work zone begins, where do you usually 
start to slow down, and at what instance do you perform a lane change if you are traveling on the right lane.

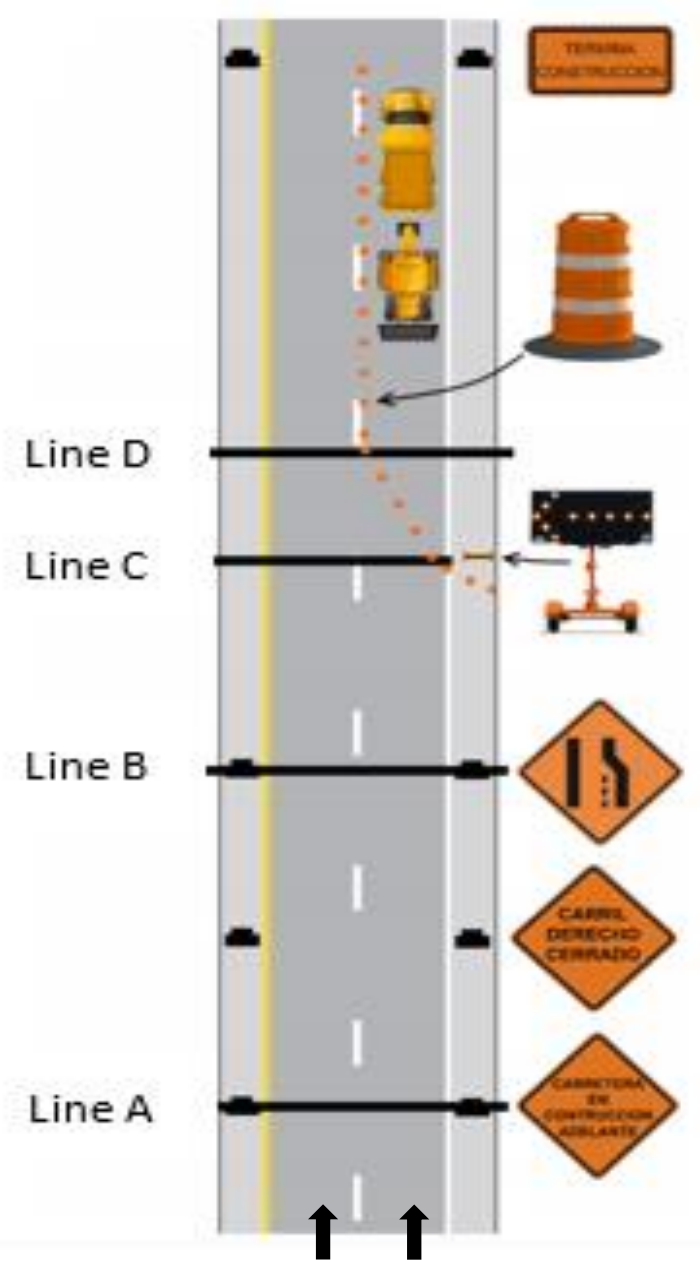

Figure 2: Illustration of a TTC of a Stationary Lane Closure on a Divided Highway.

Phase 2: Work Zone Interactive Learning Module

Based on the results of the web-based survey, it became evident that training is necessary to enhance road user and worker safety in and around work zones. A Work Zone Interactive Learning Module (WZILM) was developed to increase awareness and knowledge of work zones and TTC plans.

The participants for phase 2 were recruited using convenience sampling. The study included students enrolled in an entry-level second-year undergraduate engineering course. At this stage, the students have not taken an introductory highway design course. An email was sent to the students enrolled in the class, inviting them to participate in the study. The participation was voluntary and the informed consent and instructions on how to access the WZILM were given to participants. 


\section{Description of WZILM}

The WZILM was written in English and narrated in Spanish and was made available online. The module was developed using PowerPoint and the interactions were added using H5P, an interactive Moodle plugin. The WZILM has a duration of 15 minutes and 40 seconds and includes questions and statements embedded.

The first part of the module consists of a pre-test where respondents are asked to drag and drop, indicate true or false, and choose the best answer. These questions were repeated in a post-test.

The second part of the module includes material based on Part 6 of the MUTCD that teaches participants how to correctly identify the TTC areas of a work zone. The module includes basic definitions of highways, temporary traffic controls, and work zones. In this part, participants are shown a simulation of a non-compliant work zone, in a two-lane one-direction highway segment with the right lane closed, as shown in Figure 3.

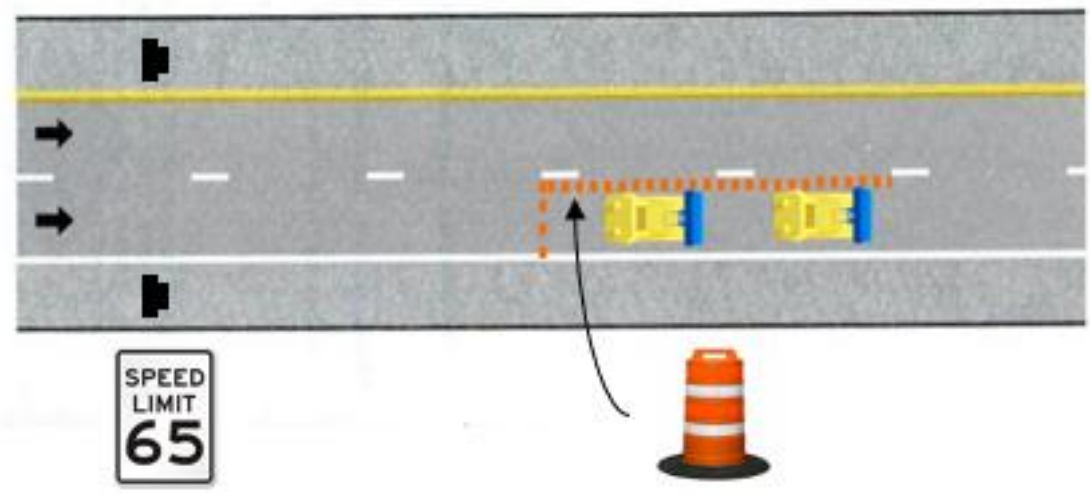

Figure 3: Non-compliant TTC shown in WZILM.

The TTC shown has no advance warning area, no transition area, and no termination area. Drivers are taken by surprise when they reach the activity area where the construction activity is taking place. The lack of a merging taper on the right lane to redirect drivers out of their normal travel path is a potentially hazardous situation. In this part of the module, participants are asked to state their level of agreement regarding the safety and adequacy of the TTC plan with the following statements:

- The work zone shown is safe for all users and workers.

- The work zone presented in the previous scene was well designed for the highway shown.

Furthermore, participants are asked what is their level of familiarity with highway work zones with the following question: How frequently do you travel through a work zone similar to the one in the previous scene?

After the simulation, the description and design principles of a TTC plan based on the MUTCD are presented. Other aspects of highway work zones are explained, such as how to design a merging taper for the transition area and how to identify the appropriate longitudinal buffer 
distance based on the pertinent speed. Typical applications of TTC plans from the MUTCD are also shown.

Figure 4 shows the starting screenshot of WZILM. Figure 5 shows the drag and drop activity for the pre-test and post-test that require participants to arrange the main components of a MUTCDcompliant TTC in the correct order. Recall that Figure 3 shows a non-compliant TTC.

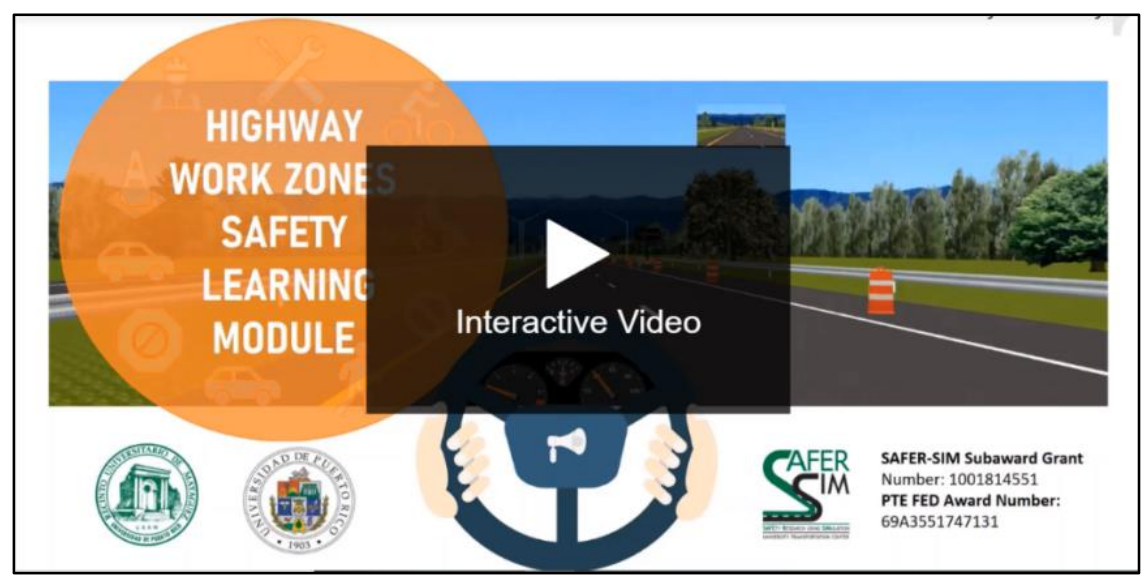

Figure 4: Screenshot of WZILM Start Slide.

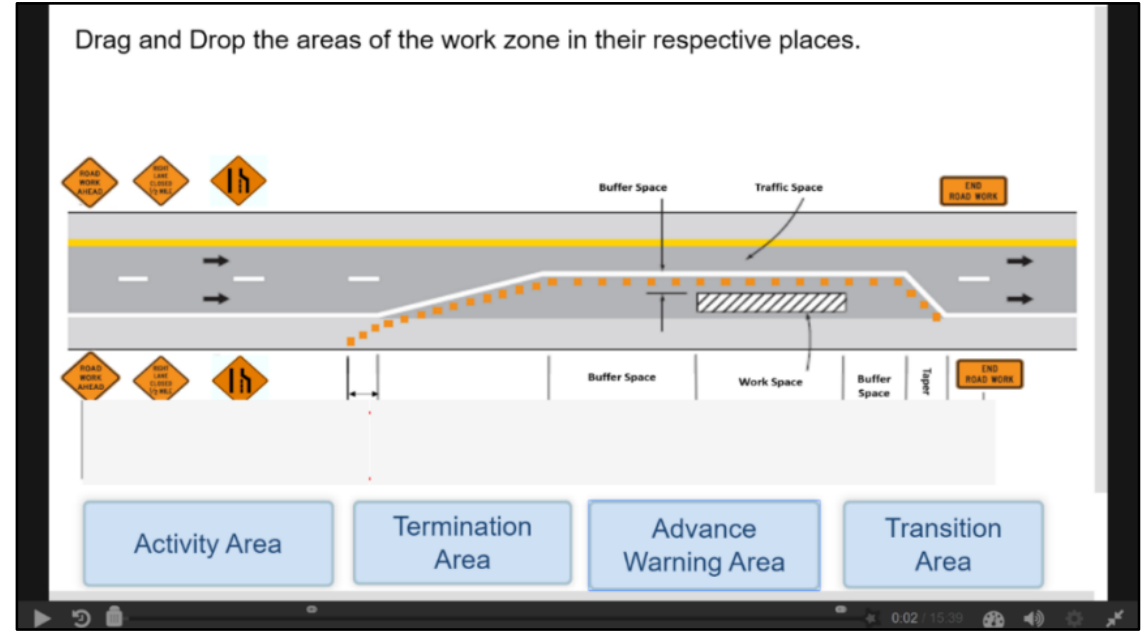

Figure 5: Screenshot of Drag and Drop Activity in WZLIM.

Figure 6 illustrates a screenshot of the video showing the advance warning area component of the TTC plan. The upper part of the image shows the simulation video of this area. The lower part is a plan view of the roadway highlighting the advance warning area with respect to the TTC. 


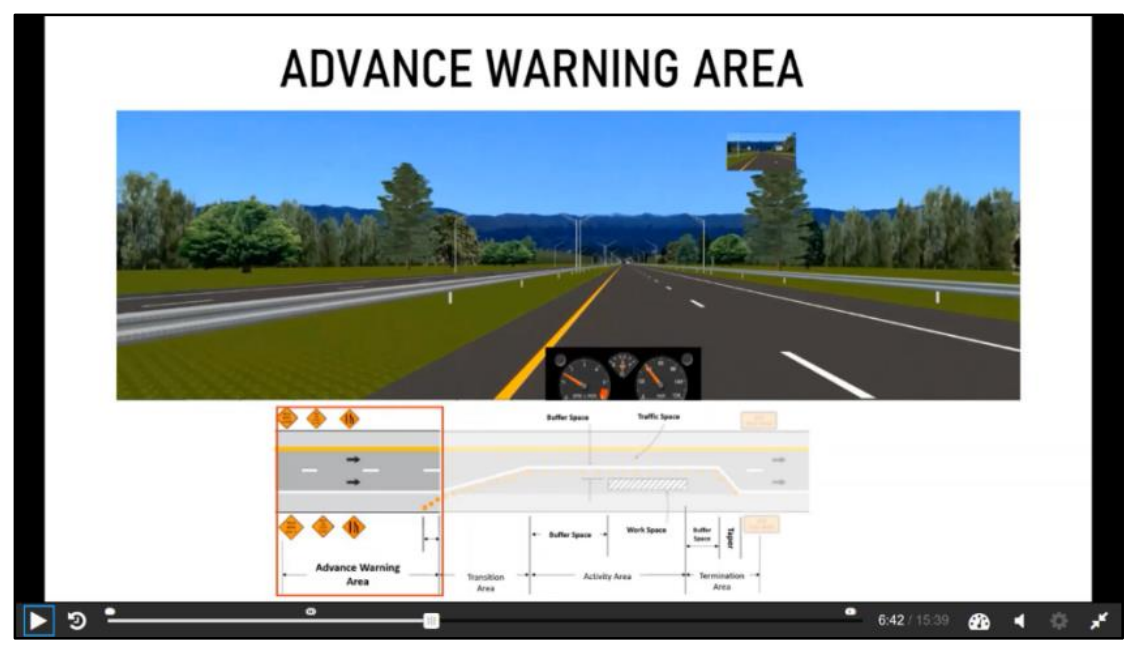

Figure 6: Screenshot of Advance Warning Component Explanation in WZILM.

\section{Results}

Phase 1 Results: Work Zone and TTC Knowledge and Perception

The online survey was administered during April and May of 2018. A total of 216 responses were recorded. In terms of gender, $53.3 \%$ of respondents were female and $46.7 \%$ male. Respondents between the ages of 18 and 25 years old corresponded to $62 \%$, while $19 \%$ were between the ages of 26 and 45 years old, and $19 \%$ were older than 46 years old.

Table 1 presents a summary of the correct responses to the questions made about the TTC zone. Almost two-thirds of the respondents $(64.81 \%)$ did not correctly recognize the beginning of the work zone. Approximately $58 \%$ of the respondents stated they usually wait to slow down until they reached a point between the last advance warning sign and the merging taper (Lines B and C). These responses imply that drivers tend to wait until the last moment (lane-closing) to adjust their running speed. However, a higher percentage of respondents $(80.6 \%)$ stated they prefer to change lanes and adjust their normal path at the beginning of the TTC zone (Lines A and B). This stated preference indicates drivers adjust their trajectory first and then wait until the last moment to reduce their speed. This behavior is considered by the MUTCD since the design of the TTC zone should apply the same road design principles that are used for regular conditions and allow vehicles to travel through the TTC zone with a speed limit reduction of no more than $10 \mathrm{mph}[1]$.

\section{Phase 2 Results - Effectiveness of WZILM}

WZILM includes three assessments: a knowledge pre-test, a mid-test perception questionnaire, and a knowledge post-test. In order to better understand the results about the effectiveness of WZILM in comparison with the results of the survey in Phase 1, the discussion in this section starts with the mid-test. Sixty students completed WZILM. Not all the students answered all the questions in the tests. 
Table 1: Survey Responses about TTC Knowledge and Perception.

\begin{tabular}{|l|l|l|}
\hline Survey Question & $\begin{array}{l}\text { Correct Responses } \\
\mathbf{N}(\%)\end{array}$ & $\begin{array}{l}\text { Correct } \\
\text { Response }\end{array}$ \\
\hline $\begin{array}{l}\text { Where do you understand that a } \\
\text { construction work zone begins? }\end{array}$ & $76(35.2)$ & Line A \\
\hline $\begin{array}{l}\text { Where you usually start to slow } \\
\text { down? }\end{array}$ & $83(38.4)$ & Line A \\
\hline $\begin{array}{l}\text { Assuming you travel in the right } \\
\text { lane, where do you change lanes? }\end{array}$ & $117(54.2)$ & Line B
\end{tabular}

Figures 7 through 9 present the answers of the students based on their perception of safety regarding the displayed work zone shown previously in Figure 3. The results indicate that 64.3\% of the students did not recognize that the conditions in the non-compliant TTC could be unsafe. Consistently, $62.5 \%$ of the respondents incorrectly stated that the highway work zone was well designed for the conditions shown in the video. Approximately $88 \%$ of respondents expressed to be familiar with similar work zones since they indicated passing through similar highway work zones at least once a month.

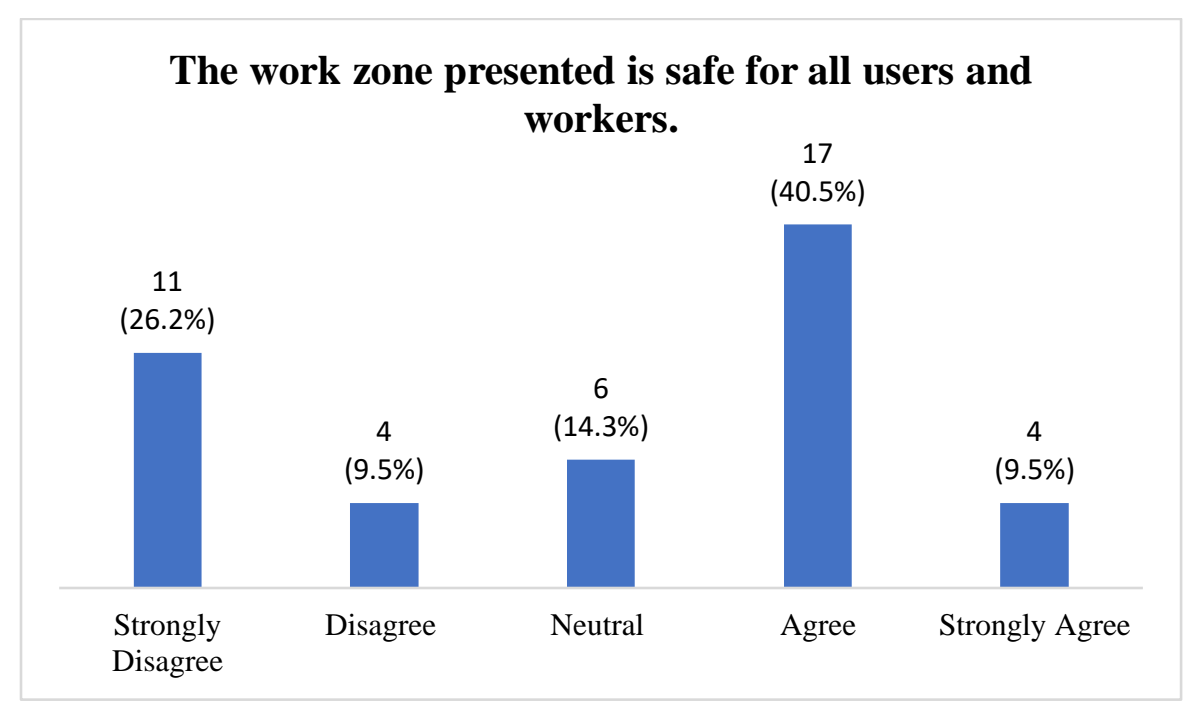

Figure 7. Answers to the Statement: The work zone* presented is safe for all users and workers. * The workzone presented is non-compliant. 


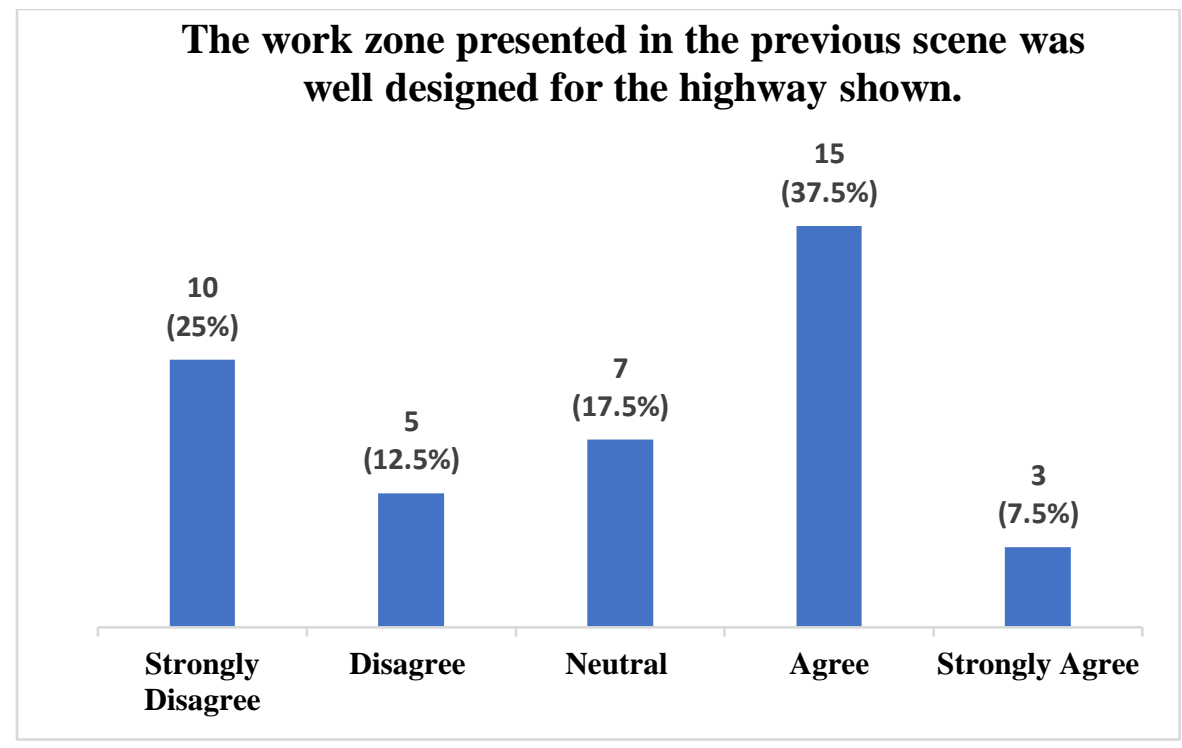

Figure 8. Answers to the Statement: The work zone* presented in the previous scene was well designed for the highway shown.

* The workzone presented is non-compliant.

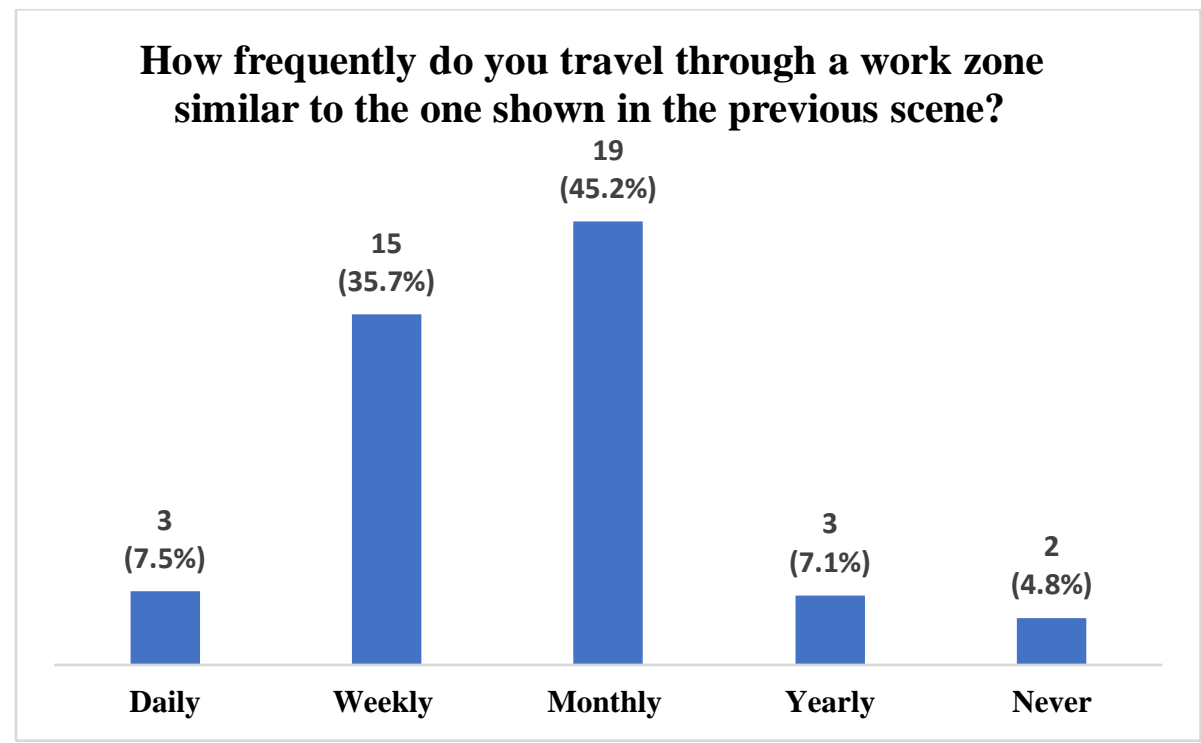

Figure 9. Answers to the Question: How frequently do you travel through a work zone* similar to the one shown in the previous scene?

* The workzone presented is non-compliant.

The results of the four pre-test and post-test answers were recorded and automatically graded by Moodle in individual student files. As previously indicated, the TTC presented in the module was not in compliance with MUTCD standards and guidance. Table 2 shows the number of correct answers increased for all the activities when comparing pre-test and post-test results. The statistical significance of the difference in the percentages of correct answers is also shown. 
Table 2: Testing Results Before and After Watching WZILM.

\begin{tabular}{|l|l|l|l|l|l|}
\hline \multirow{2}{*}{ Question } & Correct Answer & \multicolumn{2}{|l|}{ Correct Responses } & $\begin{array}{l}\text { Pre- \& } \\
\text { Post-tests } \\
\text { Difference } \\
\text { p-value }\end{array}$ \\
\cline { 3 - 6 } & $\begin{array}{l}\text { Pre-Test } \\
\%\end{array}$ & $\begin{array}{l}\text { Post-Test } \\
\%\end{array}$ & $\begin{array}{l}\% \\
\text { Change }\end{array}$ & & \\
\hline $\begin{array}{l}\text { 1. Drag \& drop work } \\
\text { zone areas in the correct } \\
\text { order. }\end{array}$ & $\begin{array}{l}\text { 1. Advanced Warning Area } \\
\text { 2. Transition Area } \\
\text { 3. Activity Area } \\
\text { 4. Termination Area }\end{array}$ & 68.3 & 75.0 & 9.8 & 0.418 \\
\hline $\begin{array}{l}\text { 2. Does the figure } \\
\text { (Figure 7) represent a } \\
\text { well-designed work zone? }\end{array}$ & False & 75.0 & 76.7 & 2.3 & 0.828 \\
\hline $\begin{array}{l}\text { 3. Does the figure } \\
\text { (Figure 8) represent a } \\
\text { well-designed work zone? }\end{array}$ & False & 63.3 & 81.7 & 29.1 & 0.025 \\
\hline $\begin{array}{l}\text { 4. Which represents the } \\
\text { beginning } \text { of a work } \\
\text { zone? }\end{array}$ & $\begin{array}{l}\text { B: Location of the first } \\
\text { warning sign in the } \\
\text { Advanced Warning Area }\end{array}$ & 31.7 & 55.0 & 73.5 & 0.010 \\
\hline
\end{tabular}

The results show different improvement levels in learning for the two similar questions about the adequacy of the two work zones (Figures 10 and 11). The statistical analysis, as evidenced by the p-values, shows that there is a statistically significant improvement in the knowledge acquired regarding questions 3 and 4 . Without providing further details about the highway operating conditions to the participants, the obvious deficiency in both TTC zones is the lack of the advance warning area. The work zone in Figure 10 also lacks the merging taper for the right lane in the transition area. If an engineer has workers' safety as a priority and this situation was in a high-speed highway, on steep slopes or has a chance of adverse weather (i.e., rain, fog, etc.), adding a longitudinal buffer before the workspace can be justified. Recognizing these factors is essential for the design of a proper TTC zone based on the prevailing conditions.

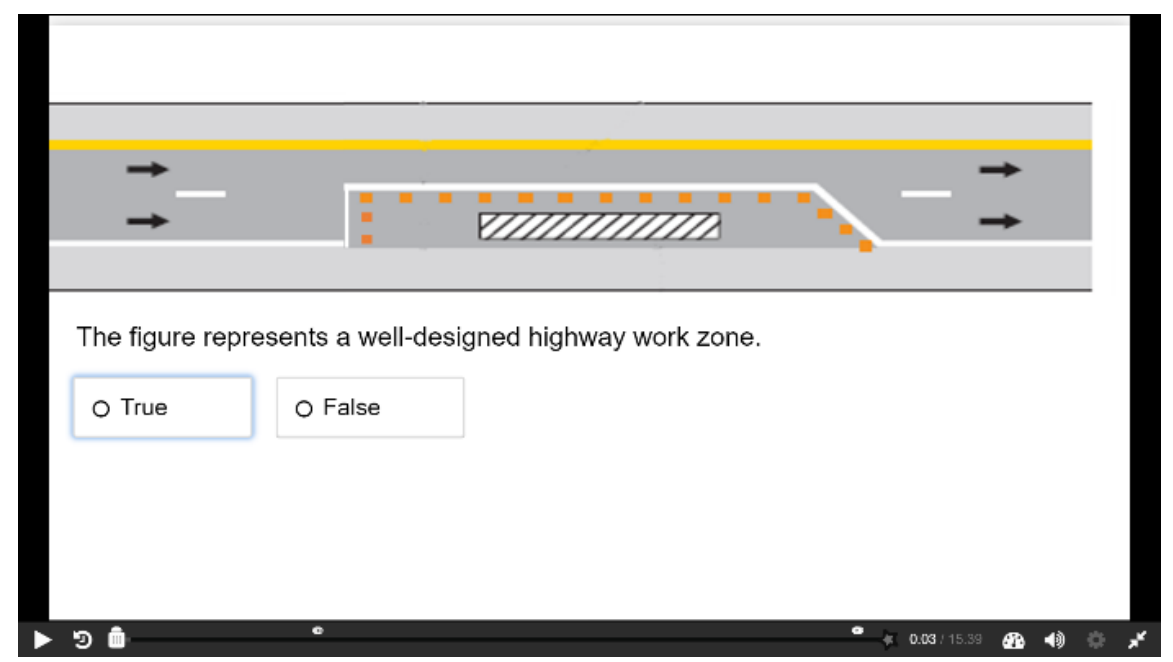

Figure 10: WZILM pre-test and post-test (Question 2). 


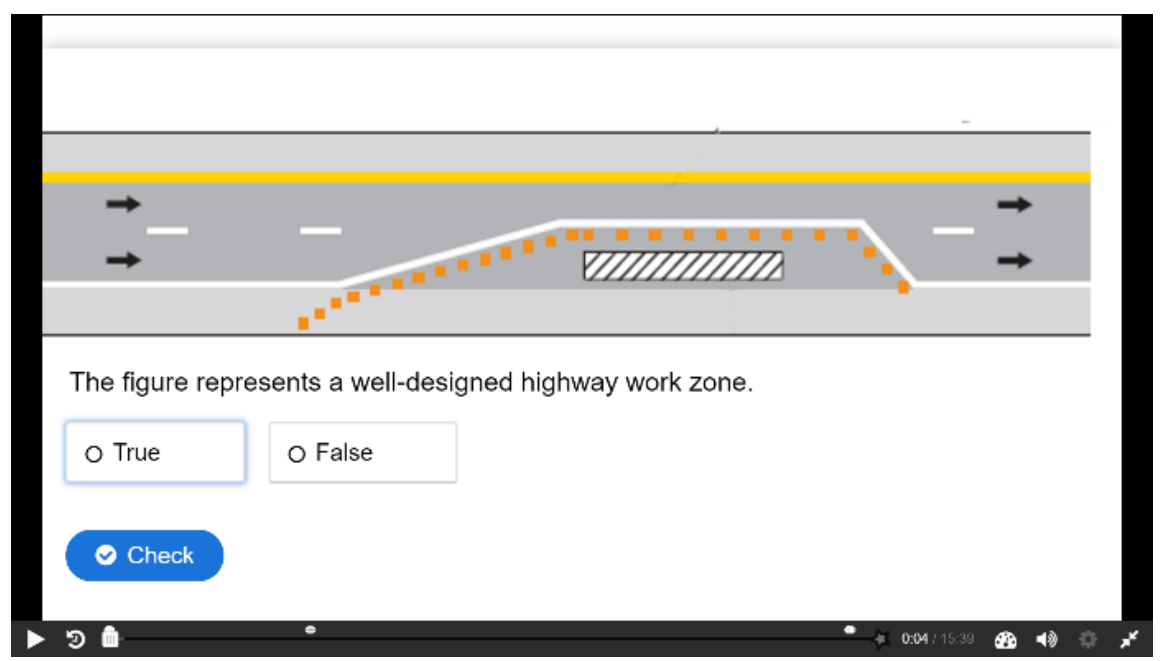

Figure 11: WZILM pre-test and post-test (Question 3).

\section{Lessons Leraned}

The results of the Survey on Work Zone and TTC Knowledge and Perception clearly indicate that there is a need to educate drivers regarding their behavior in and around workzones. The major drawback of the results was the inadequate identification of where the work zone starts and the drivers need to start adjusting their normal path and speeds prior to approaching the activity area, which according to the MUTCD is the start of the advance warning area. Clearly understanding where a work zone begins and where the driver shoud start to slow down is essential to increase safety for both road users and construction workers.

The interactive learning module that was designed for this study includes a mid-test perception questionnaire that affirms the results obtained in the survey. Furthermore, the results indicate that more than $50 \%$ of the participants believe that a non-compliant workzone is well designed and safe. Also $88 \%$ of the participants stated that they see this type of workzone at least monthly, therefore expressing that they are familiar with this type of workzone. All of the previously mentioned results are a cause of great concern. The lack of awareness regarding adequate work zone design puts road users and workers at an increased risk of injuries and fatalities.

Furthermore, even a compliant work zone can not protect road users or construction workers if the drivers do not follow the directions posted through signage, pavement markings and other temporary control devices.

The WZILM is a good start to create awareness of the importance of highway work zone safety. The online self-administered module was effective in increasing the knowledge of second-year undergraduate engineering students about TTC components. All questions showed improvement since the percentage change are positive. In particular, the question related to where the work zone begins showed a significant positive percent change (73.5\%). This is an encouraging result; however there is still a lot of room for improvement since only $55 \%$ of the participants were able to correctly identify the beginning of a work zone after the intervention. The complexity of a highway work zone might be associated with the fact that a lower than expected number of participants indicated the non-compliant TTC shown was well-designed and safe for workers and road users. However, there is a ministerial obligation that highway work zones and the different components of a highway (signage, markings, etc.) must convey a clear message and adequate 
time to respond to a first-time driver in a particular road setting, including tourists. These results need to be further analyzed to identify strategies to improve comprehension of the design of TTC zones and identify potentially unsafe roadway conditions in a work zone.

This type of learning video can be implemented throughout the curriculum in the early stages of different disciplines, to a variety of academic programs (i.e., arts and sciences, business administration, and agriculture and mechanics, among others). The WZILM is an excellent tool that has the potential to be applied to other safety-related disciplines to raise awareness and risk management. The module is cost-effective and allows the participants to learn at their own pace.

\section{Recommendations}

Based on the results of this study, the interactive learning module will be revised. The duration of the WZILM was over fifteen minutes due to the quantity of information provided to participants. The duration of the instructional video module should not exceed five minutes to address attention span limitations and improve the capacity of students to grasp the technical material. A suggestion is to divide WZILM can be divided into shorter modules of no more than 5 minutes to better address the complexity of work zones in rural and urban, high-speed vs. lowspeed highway conditions and the potential for the presence of pedestrians and cyclists in the study TTC.

Future iterations of WZILM can improve the combination of video on the upper part and the images with the sequences of the work zones (i.e., advance warning area, transition area, activity area, and termination area). This can be expanded to the explanation of similar sequential processes on other topics. The use of WZILM can be also applied to the driver learner examination process to teach about the safety implications of work zones.

\section{Acknowledgement}

This material is based upon work supported by the Safety Research Using Simulacion (SaferSim) University Transportation Center and funded by the U.S. Department of Transportation Office of the Assistant Secretary for Research and Technology under Grant No.1001814551. Any opinions, findings or conclusions expressed in this material are those of the authors and do not necessarily reflect the views of the U.S. Department of Transportation. The authors are greatly thankful to the students who participated in this study.

\section{References}

[1] Federal Highway Administration. (2009). Manual on Uniform Traffic Control Devices for Streets and Highways (Issue May).

[2] National Work Zone Safety Information Clearinghouse. (2017). 2017 National Work Zone Fatal Crashes and Fatalities. Retrieved from https://www.workzonesafety.org/crashinformation/work-zone-fatal-crashes-fatalities/\#national 
[3] Brame, C., (2007). Active learning. Vanderbilt University Center for Teaching. Retrieved January 2020 from https://cft.vanderbilt.edu/active-learning/.

[4] Weeks, B. K., \& Horan, S. A. (2013). A video-based learning activity is effective for preparing physiotherapy students for practical examinations. Physiotherapy (United Kingdom), 99(4), 292-297.

[5] Kay, R. H. (2012). Exploring the use of video podcasts in education: A comprehensive review of the literature. Computers in Human Behavior, 28(3), 820-831.

[6] Beheshti, M., Taspolat, A., Kaya, O.S., \& Sapanca, H.F. (2018). Characteristics of instructional videos. World Journal on Educational Technology: Current Issues, 10(1), 6169.

[7] Brame, C. J. (2016). Effective educational videos: Principles and guidelines for maximizing student learning from video content. CBE Life Sciences Education, 15(4), es6.1-es6.6.

[8] Mayer, R. E. (2003). 2003_Cognitive Theory of Multimedia Learning. In Educational Psychologist (Vol. 38, Issue 1, pp. 43-52).

[9] Guo, P. J., Kim, J., \& Rubin, R. (2014). How video production affects student engagement: An empirical study of MOOC videos. L@S 2014 - Proceedings of the 1st ACM Conference on Learning at Scale, 41-50.

[10] Szpunar, K. K., Khan, N. Y., \& Schacter, D. L. (2013). Interpolated memory tests reduce mind wandering and improve learning of online lectures. Proceedings of the National Academy of Sciences of the United States of America, 110(16), 6313-6317. 